\title{
Revealing Topological Influence of Phenylenediamine Unit on Physicochemical Properties of Donor-Acceptor-Donor-Acceptor Thermally Activated Delayed Fluorescent Macrocycles
}

Izumi, Saika; Nyga, Aleksandra; de Silva, Piotr; Tohnai, Norimitsu; Minakata, Satoshi; Data, Przemyslaw; Takeda, Youhei

Published in:

Chemistry - An Asian Journal

Link to article, DOI:

10.1002/asia.202001173

Publication date:

2020

Document Version

Peer reviewed version

Link back to DTU Orbit

Citation (APA):

Izumi, S., Nyga, A., de Silva, P., Tohnai, N., Minakata, S., Data, P., \& Takeda, Y. (2020). Revealing Topological Influence of Phenylenediamine Unit on Physicochemical Properties of Donor-Acceptor-Donor-Acceptor Thermally Activated Delayed Fluorescent Macrocycles. Chemistry - An Asian Journal, 15(23), 4098-4103. https://doi.org/10.1002/asia.202001173

\section{General rights}

Copyright and moral rights for the publications made accessible in the public portal are retained by the authors and/or other copyright owners and it is a condition of accessing publications that users recognise and abide by the legal requirements associated with these rights.

- Users may download and print one copy of any publication from the public portal for the purpose of private study or research.

- You may not further distribute the material or use it for any profit-making activity or commercial gain

- You may freely distribute the URL identifying the publication in the public portal 


\section{CHEMISTRY AN ASIAN JOURNAL}

www.chemasianj.org

\section{Accepted Article}

Title: Revealing Topological Influence of Phenylenediamine Unit on Physicochemical Properties of Donor-Acceptor-Donor-Acceptor Thermally Activated Delayed Fluorescent Macrocycles

Authors: Saika Izumi, Aleksandra Nyga, Piotr de Silva, Norimitsu Tohnai, Satoshi Minakata, Przemyslaw Data, and Youhei Takeda

This manuscript has been accepted after peer review and appears as an Accepted Article online prior to editing, proofing, and formal publication of the final Version of Record (VoR). This work is currently citable by using the Digital Object Identifier (DOI) given below. The VoR will be published online in Early View as soon as possible and may be different to this Accepted Article as a result of editing. Readers should obtain the VoR from the journal website shown below when it is published to ensure accuracy of information. The authors are responsible for the content of this Accepted Article.

To be cited as: Chem. Asian J. 10.1002/asia.202001173

Link to VoR: https://doi.org/10.1002/asia.202001173

\section{ACES} and Chemistry - A European Journal 


\title{
Revealing Topological Influence of Phenylenediamine Unit on Physicochemical Properties of Donor-Acceptor-Donor-Acceptor Thermally Activated Delayed Fluorescent Macrocycles
}

\author{
Saika Izumi, ${ }^{[a]}$ Aleksandra Nyga, ${ }^{[b]}$ Piotr de Silva, ${ }^{[[]]}$Norimitsu Tohnai, ${ }^{[a]}$ Satoshi Minakata, ${ }^{*[a]}$ \\ Przemyslaw Data, ${ }^{* b, \mathrm{~d}]}$ and Youhei Takeda*[a]
}

[a] S. Izumi, Prof. Dr. N. Tohnai, Prof. Dr. S. Minakata, Prof. Dr. Y. Takeda

Department of Applied Chemistry

Graduate School of Engineering, Osaka University

Yamadaoka 2-1, Suita, Osaka 5650871 (Japan)

E-mail:minakata@chem.eng.osaka-u.ac.jp; takeda@chem.eng.osaka-u.ac.jp

[b] A. Nyga, Prof. P. Data

Faculty of Chemistry

Silesian University of Technology

M. Strzody 9, 44-100 Gliwice (Poland)

E-mail: przemyslaw.data@polsl.pl

[c] Prof. P. de Silva

Department of Energy Conversion and Storage

Technical University of Denmark

Anker Engelunds Vej 301, 2800 Kgs. Lyngby (Denmark)

E-mail:pdes@dtu.dk

[d] Prof. P. Data

Centre of Polymer and Carbon Materials

Polish Academy of Science

M. Curie-Sklodowskiej 34, 41-819, Zabrze (Poland)

Supporting information for this article is given via a link at the end of the document.

\begin{abstract}
A new thermally activated delayed fluorescence (TADF)displaying macrocyclic compound $\mathbf{m}-\mathbf{1}$ comprising of two electrondonors ( $N, N$ '-diphenyl-m-phenylenediamine) and two electronacceptors (dibenzo[a,j]phenazine) has been synthesized. The macrocycle developed herein is regarded as a regioisomer of the previously reported TADF macrocycle $\mathrm{p}-1$, which has two $N, N^{\prime}$ diphenyl-p-phenylenes as the donors. To understand the influence of the topology of the phenylenediamine donors on physicochemical properties of TADF-active macrocycles, herein the molecular structure in the single crystals, photophysical properties, electrochemical behavior, and TADF properties of $\mathbf{m}-\mathbf{1}$ have been investigated compared with those of $\mathbf{p}-\mathbf{1}$. The substitution of $p$ phenylene donor with $m$-phenylene donor led to distinct positive solvatoluminochromism over the full visible-color range, unique oxidative electropolymerization, and slightly lower contribution of TADF, due to the lower CT character in the excited states.
\end{abstract}

\section{Introduction}

Organic $\pi$-conjugated electron donor-acceptor (D-A) repeating molecules, oligomers, and polymers have attracted much attention as photo- and electroactive organic materials, as the optical and electrochemical bandgaps, charge-carrier mobilities, and luminescence properties are finely tunable through structural modification. They find myriad applications in optoelectronic fields such as organic field-effect transistors (OFETs), ${ }^{[1]}$ organic photovoltaics (OPVs), ${ }^{[2]}$ organic light-emitting diodes (OLEDs), ${ }^{[3]}$ and some others. ${ }^{[4]}$ Especially, over the last decade, the D-A $\pi$ conjugated compounds with a large twisting angle around the DA-connecting bond have emerged as promising scaffolds for efficient thermally activated delayed fluorescence (TADF) materials. ${ }^{[5]}$

TADF is a fundamental phenomenon that can harvest triplet excitons to convert into the emissive singlet excitons via thermally activated reverse intersystem crossing (RISC), yielding delayed fluorescence in theoretically $100 \%$ internal quantum efficiency (IQE). Due to the high utilization efficiency of triplet excitons, purely organic TADF emitters can greatly improve external quantum efficiency (EQE) of OLEDs, and very efficient (EQE $>20 \%)$ TADF-OLEDs have been already reported. ${ }^{[6]}$ In addition to optoelectronic applications, the potency of TADF compounds as functional molecules has been also explored in the fields of photocatalysis ${ }^{[7]}$ and bio-imaging. ${ }^{[8]}$ Since the RISC rate $\left(k_{\text {RISC }}\right)$ increases as the inverse of an exponential function of the energy splitting between the singlet $\left(S_{1}\right)$ and triplet $\left(T_{n}\right)$ states $\left(\Delta E_{\mathrm{ST}}\right.$ ), a narrow $\Delta E_{\mathrm{ST}}$ and a large spin-orbit coupling (SOC) for $S_{1}-T_{n}$ transitions are the requisites for giving a large $k_{R I S C}$ and thereby efficient TADF. Since it has been believed that $\Delta E_{S T}$ is just doublet electron exchange energy $(2 J)$ of the two unpaired electrons in the excited states, the HOMO and LUMO should be decoupled. However, recent theoretical results demonstrate that the situation is more complicated, and different design strategies should be pursued. ${ }^{[9]}$ As earlier stated, a common molecular design strategy for TADF materials is connecting a lone-paircontaining $D$ and an $A$ units through a single $\sigma$-bond with a large twisting angle (ca. $90^{\circ}$ ) to ensure a narrow $\Delta E_{\mathrm{ST}}$ and a large SOC. Over the last several years, many purely organic TADF materials based on linearly or branchingly connected D-A molecular architectures with a large twist angle have been developed. ${ }^{\left[{ }^{[]}\right.}$In contrast, macrocyclic TADF emitters comprising of D-A repeating units have been scarcely explored, probably due to the synthetic challenge for constructing such molecular scaffolds. ${ }^{[10,11]}$ Due to 
the limited numbers of macrocyclic TADF compounds, little is known for the structure-property relationship (SPR) of macrocyclic TADF materials. Conversely, it would be rewarding to investigate and reveal the SPR of macrocyclic TADF materials to gain insights on the design strategy for efficient macrocyclic TADF emitters.

Recently, we have developed a thermally activated delayed fluorescent electron-donor-acceptor-donor-acceptor (D-A-DA) type $\pi$-conjugated macrocycle p-1 (Figure 1), ${ }^{[11]}$ comprising of two U-shaped electron-acceptors, i.e., dibenzo[a,j]phenazine (DBPHZ), ${ }^{[12]}$ and two $N, N$ '-diphenyl-p-phenylenediamine donors. By taking advantage of the U-shaped structure of the acceptor and proper-shaped triarylamine donor, the key macrocyclization is rather high-yielding. Notably, this emitter represents the 1st purely organic TADF macrocyclic emitting material that yields an efficient OLED device with a high external quantum efficiency (EQE), exceeding the theoretical EQE (ca 5\%.) in the OLED devices fabricated with a 1st generation fluorescent emitter. ${ }^{[13]}$ The comparison of the physicochemical properties of $\mathbf{p}-\mathbf{1}$ with its linear analog (Linear) revealed the efficacy of cyclizing the D-AD-A structure for enhancing TADF contribution in emission. We then became interested in the influence of the topology in the phenylenediamine donor unit of $\mathbf{p}-\mathbf{1}$ on its properties including TADF behavior. To date, topological influence of phenylene unit (meta versus para) on the properties of phenylene-linked linear $\pi$ electron conjugated systems, such as oligo(phenylenevinylene)s, ${ }^{[14]}$ oligo(phenylene ethynylene)s, ${ }^{[15]}$ oligo(aniline)s, ${ }^{[16]}$ phenylene-bridged bis(triarylamine) $\mathbf{s}^{[17]}$ and bis(ethynyltriarylamine)s, ${ }^{[18]}$ phenylene-linked $\mathrm{N}$-annulated perylene diimide dimers, ${ }^{[19]}$ aminostilbenes, ${ }^{[20]}$ and bis(ethynylene)phenylene-linked donor (carbazole) and acceptor (naphthalimides) compound, ${ }^{[21]}$ has been moderately explored. The topology in phenylene unit in these previously investigated $\pi$ conjugated systems gives an impact on properties such as HOMO-LUMO optical gap ${ }^{[14]}$ photoluminescence quantum yield (PLQY), ${ }^{[15]}$ spin localization of radical cation, ${ }^{[16,17]}$ the rate of charge separation, ${ }^{[19]}$ for instance. Nevertheless, such topological studies of $\pi$-conjugated macrocyclic compounds are quite limited to cyclic oligo(phenylenediamine) $\mathrm{s}^{[22]}$ and $\mathrm{B}-\pi-\mathrm{N}$ ambipolar macrocycles. ${ }^{[23]}$ To the best of our knowledge, the influence of the topology of the electron donors of the macrocyclic TADF compound has never been investigated. ${ }^{[24]}$

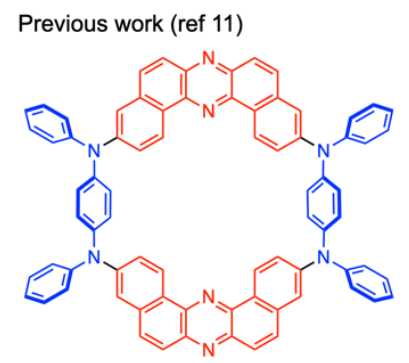

p-1
This work

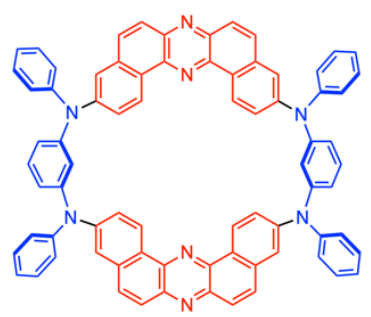

m-1
Figure 1. Structures of D-A-D-A macrocycles $\mathrm{p}-1$ and $\mathrm{m}-1$.
Herein, we disclose the synthesis, structure, and physicochemical properties of a new D-A-D-A macrocyclic compound $\mathbf{m}-\mathbf{1}$ (Figure 1), which is a regioisomer of $\mathbf{p}-\mathbf{1}$. From the comparison with $\mathbf{p - 1}$, the influence of the topology of the phenylenediamine donor unit (meta versus para) on the molecular conformation, electrochemical properties, and photophysical properties including TADF functions has been revealed.

\section{Results and Discussion}

\section{Design and synthesis of macrocycle $\mathrm{m}-1$.}

To investigate the influence of topology in the phenylenediamine donor, we designed D-A-D-A macrocycle $\mathbf{m}-\mathbf{1}$ (Figure 1), which is regarded as the meta-variant of previously reported $\mathbf{p}-1 .{ }^{[11]}$ The synthetic route to macrocycle $\mathbf{m - 1}$ is illustrated in Scheme 1 . Unsymmetrical $m$-phenylene diamine donor $\mathbf{2}$ was efficiently prepared, starting from 3-bromo-iodobenzene in 3 steps (Scheme $\mathrm{S} 1$ in the $\mathrm{SI}$ ). In a similar manner with the synthesis of macrocycle p-1, ${ }^{[11]}$ the donor 2 was coupled with 3,11-dibromodibenzo[a,j]phenazine $(2 \mathrm{Br}-\mathrm{DBPHZ})^{[12]}$ through a Pd-catalyzed double Buchwald-Hartwig amination to provide a D-A-D intermediate 3 in high yield (Scheme 1). The deprotection of the $\mathrm{N}-\mathrm{Boc}$ groups of $\mathbf{3}$ was conducted with an excess amount of trifluoroacetic acid (TFA), giving rise to 4 in a quantitative manner. The final and key macrocyclization of 4 with $2 \mathrm{Br}-\mathrm{DBPHZ}$ was completed through a Pd-catalyzed double Buchwald-Hartwig amination (Scheme 1), although the chemical yield in the macrocyclization step is much lower $(10 \%)$ than that for $\mathbf{p}-1$ (45\%). ${ }^{[11]}$ Since a significant amount of polymeric uncharacterized residue was observed in the crude ${ }^{1} \mathrm{H}$ NMR chart, this significant lowering in macrocyclization efficiency might ascribe to competing for intermolecular aminative oligomerization/polymerization pathways over the desired intramolecular cyclization.

Crystallographic analysis of single crystals and photoluminescence properties in the solid states.

Macrocycle $\mathbf{m - 1}$ is less soluble in organic solvents than $\mathbf{p - 1}$, and the recrystallization leads to tiny microcrystals. After several attempts of recrystallization, we were able to acquire yellow single crystals from a mixed solution of 1,2-dichlorobenzene and $n$ hexane solution of $\mathbf{m}-\mathbf{1}$ suitable for the X-ray diffraction crystallographic analysis (for the detailed analytical data, see the $\mathrm{SI})$. In the crystal, the macrocycle $\mathbf{m - 1}$ similarly takes a saddle conformation with p-1 (Figure 2a). ${ }^{[11]}$ When compared with the saddle conformer of $\mathbf{p}-1$, the interplane angle of the two DBPHZ panels is much smaller $\left(91^{\circ}\right)$ than that of $\mathbf{p}-1\left(148^{\circ}\right)$, due to the closer distance of the two $\mathrm{N}$ atoms on the phenylene donor (Figure 2b). The saddle-shaped macrocyclic molecules form a 1D self-assembled structure, where intermolecular DBPHZ units stack, with contact between adjacent molecules being $3.43 \AA$ (Figure 2c). Although p-1 exhibited two different polymorphs with different conformers (helical and saddle conformers), ${ }^{[11]} \mathbf{m - 1}$ formed only one conformer. 


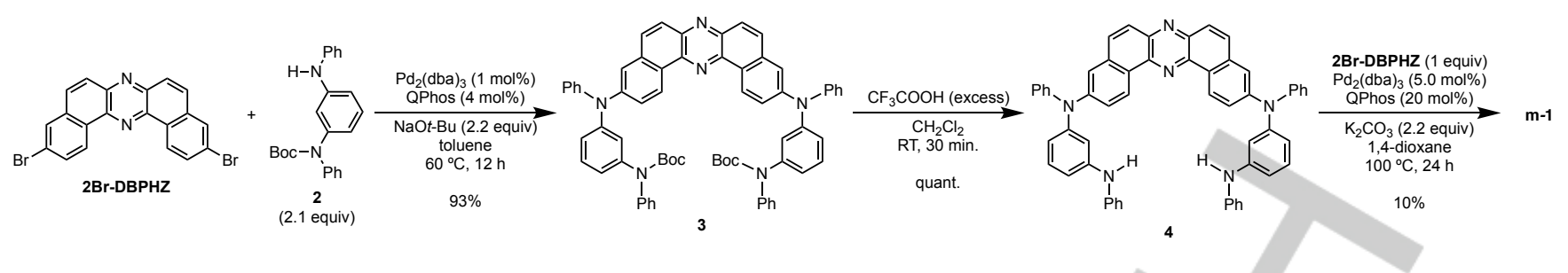

Scheme 1. Synthetic route to macrocycle $\mathbf{m}-1$.

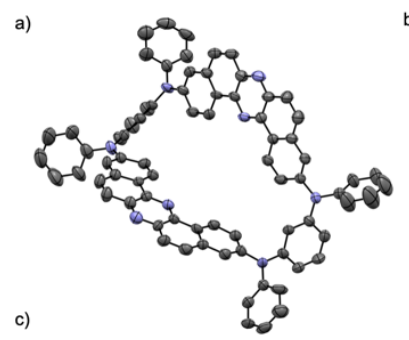

b)

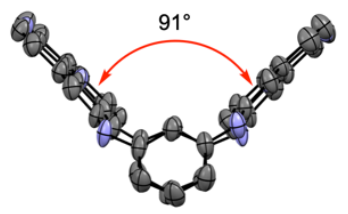

c)

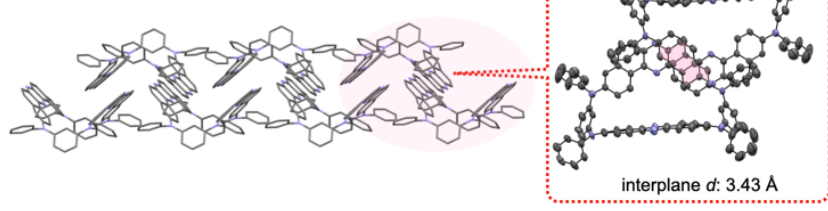

Figure 2. a) Molecular structure of $m-1$ (hydrogen atoms and solvent molecules are omitted for clarity); b) a side view of $\mathbf{m - 1}$ (hydrogen atoms, the $\mathrm{N}-\mathrm{Ph}$ groups and solvent molecules are omitted for clarity); c) packing structure of $\mathbf{m - 1}$.

Upon the irradiation of a UV light, the solids of $\mathbf{m}-1$ displayed orange photoluminescence $\left(\lambda_{\mathrm{em}} 636 \mathrm{~nm}\right)$ with a low PLQY ( $\Phi_{\mathrm{PL}} 0.04$ ) (Figure 3 ). When compared with the solid-state $\mathrm{PL}$ of the saddle conformer polymorphs of $\mathbf{p}-1$ (saddle: $\lambda_{\mathrm{em}} 654$ $\left.\mathrm{nm}, \Phi_{\mathrm{PL}} 0.01\right),{ }^{[11]}$ the emission wavelength of the solids of $\mathbf{m - 1}$ appeared in a slightly blue-shifted region. This suggests that $\mathbf{m}$ 1 has a weaker charge-transfer character in the excited states than $\mathbf{p}-1$, which is seen by the solvatochromic behavior of $\mathbf{m - 1}$ in organic solvents (vide infra).

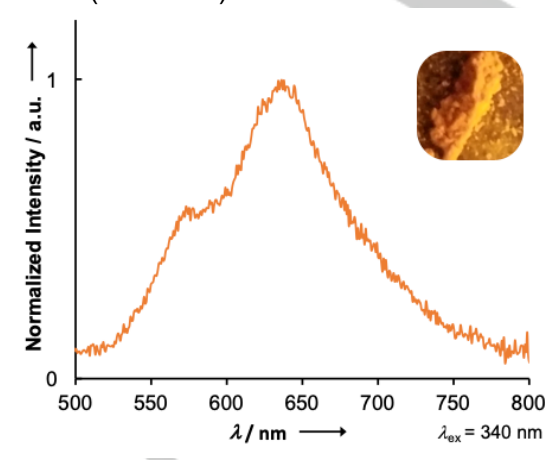

Figure 3. PL spectrum of $\mathrm{m}-1$ in the solid states. The inset photograph shows the image of emission under a UV lamp ( $\left.\lambda_{\text {ex }} 365 \mathrm{~nm}\right)$.

Steady-state photophysical properties of diluted solutions of $\mathbf{m}-1$.
To investigate the fundamental photophysical properties of $\mathbf{m}-\mathbf{1}$, the steady-state UV-vis absorption and photoluminescence $(\mathrm{PL})$ spectra of the diluted solutions $\left(c 10^{-5} \mathrm{M}\right.$ ) of $\mathbf{m}-\mathbf{1}$ were acquired (Figure $4 \mathrm{a}$ and Table 1). The solubility of macrocycle $\mathrm{m}-1$ toward cyclohexane is very low, and due to this, it was not possible to obtain well-resolved UV-vis spectra. In other solvents such as toluene, THF, $\mathrm{CH}_{2} \mathrm{Cl}_{2}, \mathrm{CHCl}_{3}$, and DMF, m-1 displayed similar UV-vis absorptions comprising of intramolecular charge-transfer (ICT) transition at around $\lambda_{\text {abs }} 470 \mathrm{~nm}$, which is mainly ascribed to the HOMO $\rightarrow$ LUMO transition (for the details of theoretical calculations, see the $\mathrm{SI}$ ), and $\pi-\pi^{*}$ transitions at around $\lambda_{\text {abs }} 315$ $\mathrm{nm}$ (Figure 3a, dotted lines). The simulated absorption spectra of $\mathrm{m}-1$ in toluene, using the conformation found in the single crystal (saddle shape), nicely agreed with the experimental one (Figure S11). Also, according to the conformational search, the saddle shape is the most stable conformer (ca. $4 \mathrm{kcal} / \mathrm{mol}$ more stable than the secondarily stable conformer). Taken together, we can conclude that almost all the $\mathrm{m}-1$ molecules take saddle conformer in solutions, as is the case with $\mathbf{p}-1 . .^{[11]}$ The absorption onset in the lower energy region ( $\lambda 500-550 \mathrm{~nm})$ slightly redshifts as the solvent polarity increases (Figure $4 a$ ), indicating the absorption peaked at around $\lambda_{\text {abs }} 470 \mathrm{~nm}$ is ascribed to a hybrid type CT. This characteristic is very similar to that of $p-1 .{ }^{[11]}$ When the absorption spectra of $\mathbf{m - 1}$ are compared with those of $\mathbf{p}-1,{ }^{[10]}$ one would notice that as a whole the spectra shapes are very similar to each other but different in absorption peaks. Both of the ICT and $\pi-\pi^{*}$ bands of $\mathbf{m}-1$ locales in the bluer region than p-1 by ca. $10 \mathrm{~nm}$, due to shorter effective conjugation length of the phenylenediamine unit of $\mathbf{m}-\mathbf{1}$ than $\mathbf{p}-1$. The experimental absorption spectra for $\mathbf{m}-\mathbf{1}$ and $\mathbf{p}-\mathbf{1}$ qualitatively agree with the calculated ones (Figure S11), which were calculated by the TDDFT method using an optimally tuned range separated hybrid functional (WPBE) and a state-specific non-equilibrium PCM solvation model. The macrocycle $\mathbf{m}-\mathbf{1}$ nicely displayed positive solvatoluminochromism as a function of solvent polarity (Figure 4a). Given the UV-vis absorption spectra are less affected by solvent polarity than PL spectra, macrocycle $\mathbf{m}-1$ has a much larger charge transfer nature in the excited states rather than in the ground states, as is the case with $\mathbf{p - 1} .^{[11]} \mathrm{A}$ large difference in PL behavior of $\mathbf{m - 1}$ and $\mathbf{p - 1}$ is the degree of solvatochromism, which indicates a much larger CT character of p-1 in the excited states. It would be interesting to note that the solvatochromic behavior of $\mathbf{m - 1}$ is very similar with that of 3,11-bis $(N, N$ diphenylamino)-substituted $\mathrm{DBPHZ},{ }^{[25]}$ suggesting that the topology of the phenylene unit in the $D-A-D-A$ macrocycles strongly affects the CT nature in the excited states, probably due to the difference in effective $\pi$-conjugation length through the molecule. 
Since TADF is irradiated via RISC from the triplet excited states, TADF emission is sensitive toward the presence of oxygen gas, which promptly quenches the long-lived triplet excited states through energy transfer or electron transfer mechanisms. In fact, the PL intensity of the TADF-active p-1 compound in degassed toluene drastically decreased upon the injection of oxygen gas. ${ }^{[11]}$ The $\mathrm{PL}$ intensity of the degassed dichloromethane and THF solutions of $\mathbf{m}-\mathbf{1}$ dropped after the saturation with oxygen gas by about $10 \%$ (Figure $4 b$ and $c$ ), indicating the involvement of triplet states character in the PL. It is noted that the decline rate of $\mathbf{m}-\mathbf{1}$ is much smaller than that of p-1 (ca. $60 \%$ ), which indicates less TADF contribution in PL of solutions of $\mathbf{m}-\mathbf{1}$ than those of $\mathbf{p}-\mathbf{1}$. The TADF contribution is much smaller in the toluene solvent ( $3 \%$, Figure S8), which suggests that the decrease of the RISC component is mostly due to the $\Delta E_{\text {st }}$ gap.
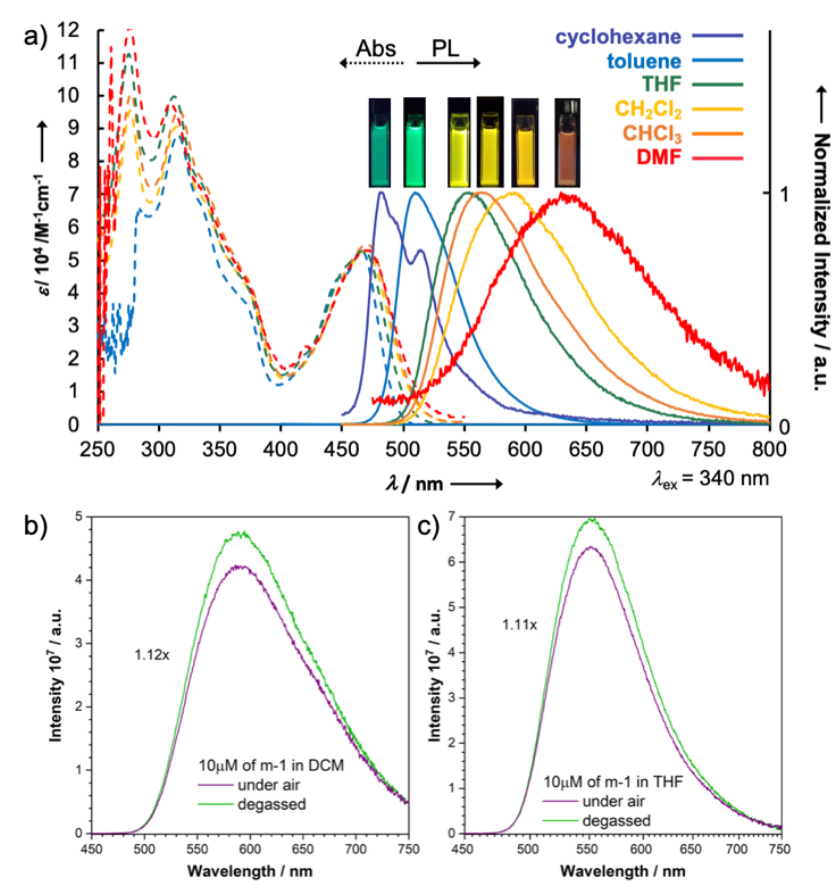

Figure 4. a) UV-vis absorption and PL spectra of solutions of $\mathbf{m}-\mathbf{1}$ in various solvents $\left(\mathrm{c} \sim 10^{-5} \mathrm{M}\right)$; b) PL spectra of $\mathbf{m - 1}(10 \mu \mathrm{M})$ in b) dichloromethane and c) THF with aerated (purple lines) and degassed (green lines).

Table 1. Summary of steady-state photophysical data of solutions of $\mathbf{m}-\mathbf{1}$.

\begin{tabular}{lccc}
\hline Solvent & \\
\hline Cyclohexane & $\lambda_{\text {abs }}[\mathrm{nm}]$ & $\lambda_{\text {em }}[\mathrm{nm}]$ & $\Phi_{\mathrm{P}}{ }^{[\mathrm{b}]}$ \\
\hline Toluene & - & 481 & 0.30 \\
\hdashline $\mathrm{THF}$ & $285,316,466$ & 509 & 0.39 \\
\hdashline $\mathrm{CH}_{2} \mathrm{Cl}_{2}$ & $275,313,467$ & 554 & 0.46 \\
\hline $\mathrm{CHCl}_{3}$ & $277,315,469$ & 591 & 0.43 \\
\hline $\mathrm{DMF}$ & $277,316,470$ & 564 & 0.35 \\
\hline
\end{tabular}

[a] Concentration: $10^{-5} \mathrm{M}$. [b] Determined with an integrated sphere. [c] Saturated solution (concentration $<10^{-6} \mathrm{M}$ ) was used, due to the low solubility in cyclohexane.

\section{Electrochemistry.}

The electrochemical behavior of $\mathbf{m}-\mathbf{1}$ was investigated with the cyclic voltammetry (CV) method. The cyclic voltammogram displayed one reversible reduction at ${ }^{\text {red }} E_{1 / 2}-1.93 \mathrm{~V}$ and one irreversible oxidation at ${ }^{\circ x} E_{1 / 2} 0.41 \mathrm{~V}$ (Figure $5 \mathrm{a}$ ). According to the oxidation and reduction potentials, the HOMO and LUMO energy levels of $\mathbf{m}-\mathbf{1}$ are calculated as $-5.51 \mathrm{eV}$ and $-3.17 \mathrm{eV}$, respectively. These values are close to the HOMO of the donor unit $N, N, N^{*}, N^{*}$-tetraphenyl-m-phenylenediamine $(-5.52 \mathrm{eV})^{[26]}$ and the LUMO of the acceptor unit DBPHZ $(-3.22 \mathrm{eV}),{ }^{[12]}$ respectively. This suggests that the HOMO and LUMO are localized on the donor and acceptor units, respectively, and which is favorable for achieving small $\Delta E_{\mathrm{ST}}$. It is noted that $\mathbf{m}-1$ showed significantly different electrochemical behavior when compared to $\mathbf{p}-\mathbf{1}$. The macrocycle $\mathbf{m}-\mathbf{1}$ displayed only one irreversible oxidation peak at the potential $0.46 \mathrm{~V}$ (Figure 5a). When the cycle was repeated, the peak current was increased (Figure $5 b$ ), indicating the oxidative polymerization of $\mathbf{m - 1}$ on the electrode. The polymerization started at around $0.30 \mathrm{~V}$, and the onset potential gradually shifted to the lower regime in every scan (Figure $5 b$ ). Since the macrocycle p-1 shows distinct electrochemically and chemically reversible 2 step oxidation at a similar potential, ${ }^{[11]}$ the polymerization of $\mathbf{m}-1$ should be ascribed to the difference in phenylene topology. This significant difference in the electrochemical behavior would be rationalized by the spin density distribution of diradical dication generated by the 1 st oxidation step (Figure $5 \mathrm{c}$ and Figure S14). In both cases, the spin densities are largely localized on the phenylene donor units, but $m-1^{\cdots+2}$ has a larger density at the o-positions of the amino units (Figure 5c) when compared with p-1 ${ }^{\cdots+2}$ (Figure $5 c$ ), probably due to the decoupling of conjugation in the phenylene unit. In addition to the difference in the spin density, the opositions of the amino units in $\mathbf{m - 1} \mathbf{1}^{\cdot+2}$ are sterically much less congested than $\mathbf{p - 1} \mathbf{1}^{\cdots+2}$ (Figure $5 c$ ). Taken together, we suppose that $\mathbf{m}-1$ more easily undergoes oxidative polymerization at the o-position of the amino units than $p-1$. Since within the EL devices organic emitters are electrically excited, this unstable electrochemical behavior of $\mathrm{m}-1$ might not be suitable for the application of $\mathbf{m}-\mathbf{1}$ as an emitter for OLEDs. Instead, such an electropolymerization behavior of $\mathbf{m}-\mathbf{1}$ might find alternative electroactive material applications such as electrochromic devices (Figure S7) or semiconducting polymeric materials.

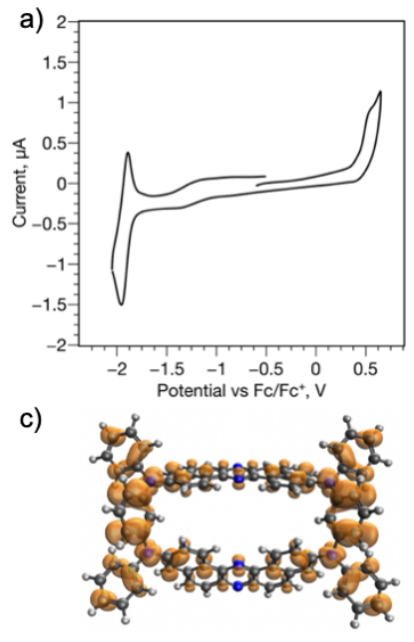

$\mathbf{m}-1 \cdot \cdots+2$
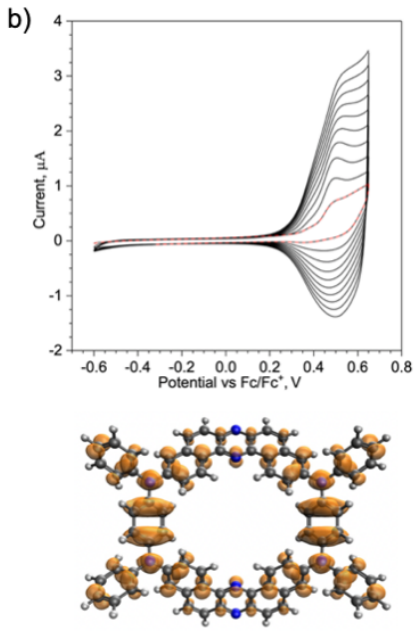

$p-1 \cdots+2$ 
Figure 5. a) Cyclic voltammogram of $m-1$, b) sweep-repeated cyclic voltammograms of $\mathbf{m}-\mathbf{1}$ in the positive potential regime; c) spin density of diradical dications of $\mathbf{m}-\mathbf{1}$ and $\mathbf{p}-\mathbf{1}$ calculated at the PBEO/aug-cc-pVDZ level.

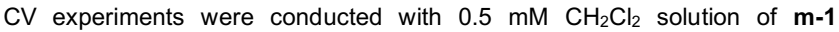
containing $0.1 \mathrm{M}(n-\mathrm{Bu})_{4} \mathrm{NBF}_{4}$ supporting electrolyte using Pt disc as a working electrode, $\mathrm{Pt}$ wire as a counter electrode, and $\mathrm{Ag}$ wire as the reference electrode. The potential was scanned at the rate of $50 \mathrm{mV} \mathrm{s}^{-1}$.

\section{Time-Resolved Spectroscopic Analysis.}

To investigate the detailed photophysics of $\mathbf{m}-\mathbf{1}$, time-resolved spectroscopic analysis of a blending film (1wt $\% \mathbf{m}-1$ in Zeonex $®$, and $10 \mathrm{wt} \% \mathbf{m}-1$ in CBP) was conducted (Figure 6). Prompt emission (time delay: $5 \mathrm{~ns}$ ) at $80 \mathrm{~K}$ and $300 \mathrm{~K}$ from the film displayed Gaussian-type spectra centered at around $520 \mathrm{~nm}$ (blue and black lines, Figure 6a, respectively). It should be noted that at a delayed emission observed at $100 \mu$ s at ambient temperature $(300 \mathrm{~K})$ nicely matched with the prompt emission (red line, Figure 6a), indicating the delayed emission is radiated from the singlet excited state $\left(S_{1}\right)$. The slope of the plot of the integral of the delayed emission intensity against the laser pulse energy is 1.00 (Figure S9), confirming the delayed emission of $\mathbf{m}-\mathbf{1}$ in the film is TADF. The phosphorescence spectra (green, Figure 6a) displayed one similar to $\mathrm{DBPHZ}\left({ }^{3} \mathrm{LE}_{\mathrm{A}}\right),{ }^{[12]}$ which is characteristic to DBPHZ-cored D-A-D compounds $\left.{ }^{[5]}\right]$ and macrocycle $\mathbf{p}-\mathbf{1}^{\left[{ }^{[1]}\right.}$ The triplet energy $\left(E_{\mathrm{T} 1}\right)$ calculated from the phosphorescence spectra is $2.39 \mathrm{eV}$, which is a little bit higher than that of $\mathbf{p}-1\left(E_{\mathrm{T} 1}=2.19 \mathrm{eV} \text { in Zeonex }{ }^{\circledR}\right)^{[11]}$ but almost the same as those of DBPHZ-cored twisted D-A-D TADF emitters. ${ }^{[5]]}$ This significant increase in the $T_{1}$ energy when compared to $p-1$ should be derived from the break in the $\pi$ conjugation by the meta substitution pattern. The singlet excited state $\left({ }^{1} \mathrm{CT}\right)$ of $\mathbf{m - 1}$ is also destabilized when compared to that of $\mathbf{p}-1$, giving higher singlet energy $\left(E_{\mathrm{S} 1}=2.70 \mathrm{eV}\right)$, which is also higher than those of previously reported D-A-D TADF compounds by about $0.3 \mathrm{eV}$. As a result, $\Delta E_{\mathrm{ST}}$ of $\mathbf{m}-1$ in Zeonex $®$ is $0.31 \mathrm{eV}$, which is a little bit wider than that of $\mathbf{p}-1(0.24 \mathrm{eV}) .^{[11]}$ This was qualitatively reproduced by the theoretical calculations: ${ }^{\text {calc }} \Delta E_{\mathrm{ST}}$ for $\mathbf{m}-\mathbf{1}$ is $0.37 \mathrm{eV}$ (Table S2) and calc $\Delta E_{\mathrm{ST}}$ for $\mathbf{p}-\mathbf{1}$ is 0.30 $\mathrm{eV} .{ }^{[11]}$ What is also important in comparison with $\mathrm{p}-1$, meta-type macrocycle $\mathbf{m}-1$ in CBP does not present TADF emission, or the TADF emission component is very weak. The time-resolver analysis in the CBP matrix did not reveal a delay component, and even at low temperatures, the phosphorescence was not observed (Figure $6 b$ and $d$ ). Such behavior excludes this compound as an efficient OLED emitter. Taken together with the electrochemical instability of $\mathbf{m}-\mathbf{1}$, the analysis of $\mathbf{m}-\mathbf{1}$ in an OLED device was not performed.

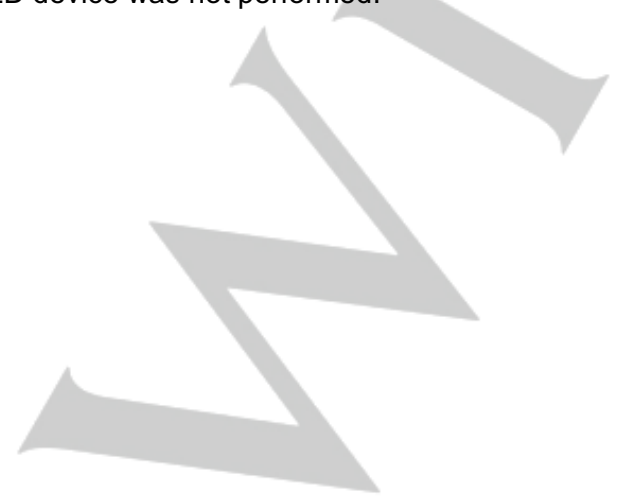

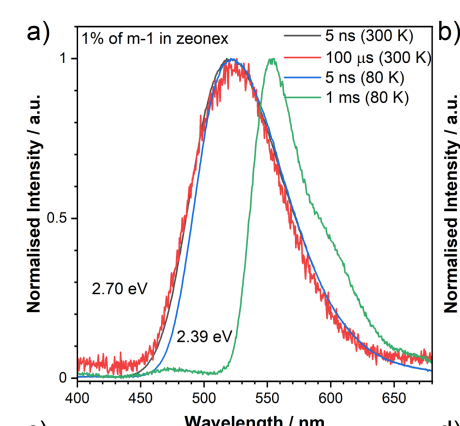
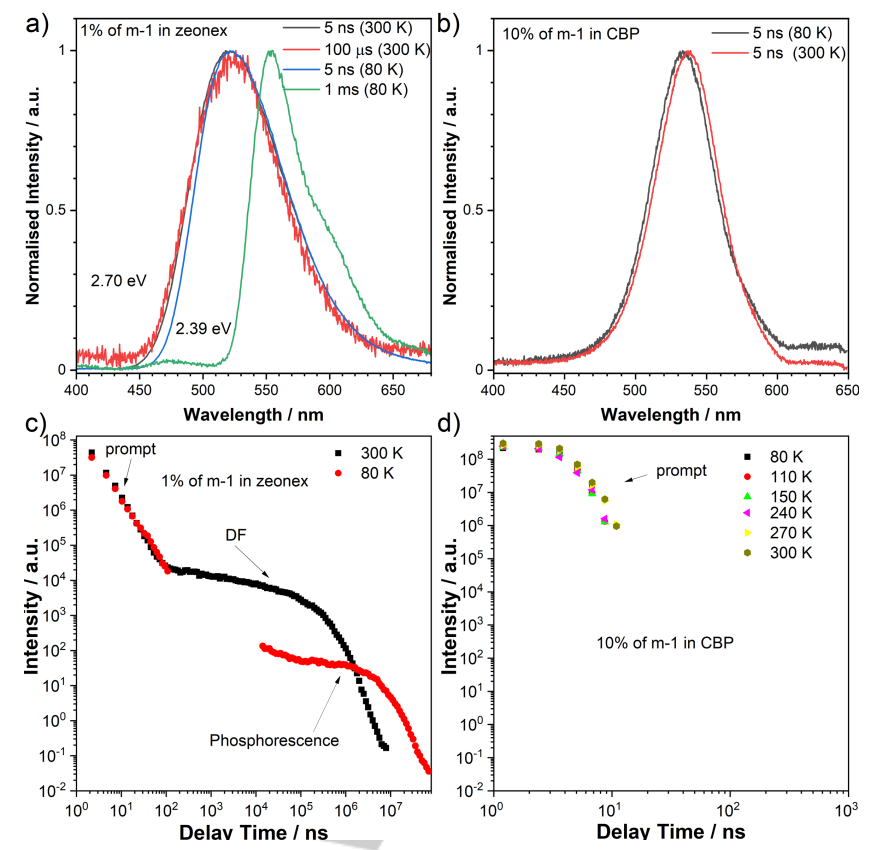

d)

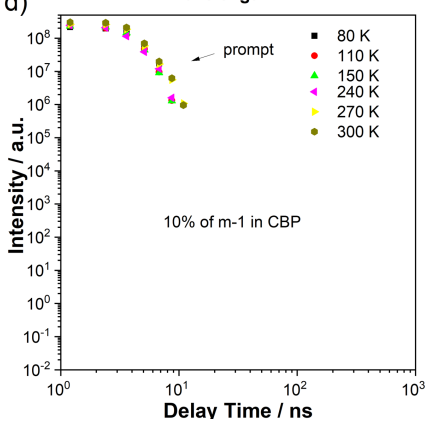

Figure 6. Prompt fluorescence, delayed fluorescence, and phosphorescence spectra of (a) $1 \% \mathrm{~m}-1$ in Zeonex, (b) $10 \% \mathrm{~m}-1$ in CBP (w/w) thin films. Photoluminescence decay of (c) $1 \% \mathrm{~m}-1$ in Zeonex, (d) $10 \% \mathrm{~m}-1$ in CBP (w/w) thin films.

\section{Conclusion}

In summary, we have successfully synthesized and characterized a new donor-acceptor-repeating $\pi$-conjugated macrocycle $\mathbf{m}-\mathbf{1}$. In the single crystals, $m-1$ takes a saddle conformer with a larger bending angle than that of $\mathbf{p - 1}$, due to the shorter distance between two amino unit. The absorption and photoluminescence spectra of solutions along with theoretical calculations revealed the shorter effective length and weaker charge-transfer character in the excited states of $\mathbf{m - 1}$ than those of $\mathbf{p}-1$, which allowed distinct solvatoluminochromism of $\mathbf{m - 1}$ over the full range of visible-light regime. The topology of the phenylenediamine donors significantly gives impacts on the distribution of the spin-density on the donor units and thereby results in unique oxidative electropolymerization. Time-resolved spectroscopy revealed that the $\Delta E_{\mathrm{ST}}$ of $\mathbf{m}-1$ is slightly larger than that of $\mathbf{p}-\mathbf{1}$, leading to weaker TADF character. Although $\mathbf{m}-\mathbf{1}$ would be less promising as TADF-OLED emitting materials, yet, the compound $\mathbf{m}-\mathbf{1}$ represents a rare example of a TADF macrocyclic compound and could find other applications by taking advantages of distinct solvatoluminochromism and electropolymerization.

\section{Acknowledgments}

P.D and A.N. acknowledge the support received from the First Team program of the Foundation for Polish Science co-financed by the European Union under the European Regional Development Fund (project number: POIR.04.04.00-004668/17-00). Y.T. and P.D. acknowledge the EU's Horizon 2020 for funding the OCTA project under grant agreement No. 778158. Y.T. acknowledges a Grant-in-Aid for Scientific Research on 
Innovative Area "Aquatic Functional Materials: Creation of New Materials Science for Environment-Friendly and Active Functions" (JSPS KAKENHI Grant Number JP19H05716) from the MEXT (Ministry of Education, Culture, Science and Technology, Japan), and the Continuation Grants for Young Researchers from the Asahi Glass Foundation. We acknowledge Prof. Seihou Jinnai and Yutaka le at Osaka University for the kind assistance of the purification of materials by sublimation.

Keywords: macrocycles• thermally activated delayed fluorescence organic light-emitting diodes • donor-acceptor • charge transfer

[1] a) M. Li, C. An, W. Pisula, K. Müllen, Acc. Chem. Res. 2018, 51, 11961205; b) J. D. Yuen, F. Wudl, Energy Environ. Sci. 2013, 6, 392-406.

[2] J. Roncali, I. Grosu, Adv. Sci. 2019, 6, 1801026/1-27.

[3] L. Duan, J. Qiao, Y. Sun, Y. Qiu, Adv. Mater. 2011, 23, 1137-1144.

[4] L Beverina, G. A. Pagani, Acc. Chem. Res. 2013, 47, 319-329.

[5] a) Y. Tao, K. Yuan, T. Chen, P. Xu, H. Li, R. Chen, C. Zheng, L. Zhang, W. Huang, Adv. Mater. 2014, 26, 7931-7958; b) R. Czerwieniec, M. J. Leitl, H. H. H. Homeier, H. Yersin, Coord. Chem. Rev. 2016, 325, 2-28; c) F. B. Dias, T. J. Penfold, A. P. Monkman, Methods Appl. Fluoresc. 2017, 5, 012001; d) Z. Yang, Z. Mao, Z. Xie,Y. Zhang, S. Liu, J. Zhao, J. Xu, Z. Chi, M. P. Aldred, Chem. Soc. Rev. 2017, 46, 915-1016; e) M. Y. Wong, E. Zysman-Colman, Adv. Mater. 2017, 29, 1605444; f) M. Sarma, K.-T. Wong, ACS Appl. Mater. Interfaces 2018, 10, 1927919304; g) X.-K. Chen, D. Kim, J.-L. Brédas, Acc. Chem. Res. 2018, 51, 2215-2224; h) Y. Liu, C. Li, Z. Ren, S. Yan, M. R. Bryce, Nat. Rev. Mater. 2018, 3, 18020; i) P. Data, Y. Takeda, Chem. Asian J. 2019, 14, 1613-1636; j) Y. Takeda, P. Data, S. Minakata, Chem. Commun. 2020, $56,8884-8894$.

[6] a) H. Kaji, H. Suzuki, T. Fukushima, K. Shizu, K. Suzuki, S. Kubo, T. Komino, H. Oiwa, F. Suzuki, A. Wakamiya, Y. Murata, C. Adachi, Nat. Commun. 2015, 6, 8476/1-8; b) J. W. Sun, J. Y. Baek, K.-H. Kim, C.-K. Monn, J.-H. Lee, S.-K. Kwon, Y.-H. Kim, J.-J. Kim, Chem. Mater. 2015, 27, 6675-6681; c) L.-S. Cui, J. U. Kim, H. Nomura, H. Nakanotani, C. Adachi, Angew. Chem. 2016, 128, 6978-6982; Angew. Chem. Int. Ed. 2016, 55, 6864-6868; d) S. Y. Lee, C. Adachi, T. Yasuda, Adv. Mater. 2016, 28, 4626-4631; e) D. Chen, K. Liu, L. Gan, M. Liu, K. Gao, G. Xie, Y. Ma, Y. Cao, S.-J. Su, Adv. Mater. 2016, 28, 6758-6765; f) I. S. Park, H. Komiyama, T. Yasuda, Chem. Sci. 2017, 8, 953-960; g) Y. H. Lee, S. Park, J. Oh, J. W. Shin, J. Jung, S. Yoo, M. H. Lee, ACS Appl. Mater. Interfaces 2017, 9, 24035-24042; h) Y. Liu, L. Hua, S. Yan, Z. Ren, Nano Energy 2020, 73, 104800/1-8.

[7] a) J. Luo, J. Zhang, ACS Catal. 2016, 6, 873-877; b) A. A. Mousawi, D. M. Lara, G. Noirbent, F. Dummur, J. Toufaily, T. Hamieh, T.-T. Bui, F. Goubard, B. Graff, D. Gimes, J. P. Fouassier, J. Lalevée, Macromolecules 2017, 50, 4913-4926; c) E. Speckmeier, T. G. Fischer, K. Zeitler, J. Am. Chem. Soc. 2018, 140, 15353-15365.

[8] a) X. Xiong, F. Song, J. Wang, Y. Zhang, Y. Xue, L. Sun, N. Jiang, P. Gao, L. Tian, X. Peng, J. Am. Chem. Soc. 2014, 136, 9590-9597; b) T. Li, D. Yang, L. Zhai, S. Wang, B. Zhao, N. Fu, L. Wang, Y. Tao, W. Huang, Adv. Sci. 2017, 4, 1600166/1-11; c) Z. Zhu, D. Tian, P. Gao, K. Wang, Y. Li, X. Shu, J. Zhu, Q. Zhao, J. Am. Chem. Soc. 2018, 140, 17484-17491; d) F. Ni, Z. Zhu, X. Tong, M. Xie, Q. Zhao, C. Zhong, Y. Zou, C. Yang, Chem. Sci. 2018, 9, 6150-6155; e) S. Kumar, S. M. Pegu, S. K. Behera, S. K. Narra, P. Thilagar, Chem. Asian. J. 2019, 14, 45884593; f) F. Ni, Z. Zhu, X. Tong, W. Zeng, K. An, D. Wei, S. Gong, Q. Zhao, X. Zhou, C. Yang, Adv. Sci. 2019, 6, 1801729/1-10; g) X. Li, G. Baryshnikov, C. Deng, X. Bao, B. Wu, Y. Zhou, H. Ågren, L. Zhu, Nat. Commun. 2019, 10, 731/1-9; h) Q. Zhang, S. Xu, M. Li, Y. Wang, N. Zhang, Y. Guan, M. Chen, C.-F. Chen, H.-Y. Hu, Chem. Commun. 2019, 55, 5639-5642; i) C. J. Christopherson, D. M. Mayder, J. Poisson, N. R. Paisley, C. M. Tonge, Z. M. Hudson, ACS Appl. Mater. Interfaces 2020, 12, 20000-20011; j) M Luo, X. Li, L. Ding, G. Baryshnikov, S. Shen, M. Zhu, L. Zhou, M. Zhang, J. Lu, H. Ågren, X.-D. Wang, L. Zhu, Angew.
Chem. 2020, 132, 17166-17173; Angew. Chem., Int. Ed. 2020, 59, 17018-17025.

[9] a) P. de Silva, C. A. Kim, T. Zhu, T. Van Voorhis, Chem. Mater. 2019, 31, 6995-7006; b) P. de Silva, J. Phys. Chem. Lett. 2019, 10, 56745679.

[10] a) N. Uchida, T. Sato, J. Kuwabara, Y. Nishimura, T. Kanbara, Chem Lett. 2014, 43, 459-461; b) Y. Hu, Z. Wang, X. Jiang, X. Cai, S.-J. Su, F. Huang, Y. Cao, Chem. Commun. 2018, 54, 7850-7853; c) Y. Hu, J. Yao, Z. Xu, Z. Wang, L. Li, S.-J. Su, D. Ma, F. Huang, Sci. China Chem. 2020, 63, 897-903.

[11] S. Izumi, H. F. Higginbotham, A. Nyga, P. Stachelek, N. Tohnai, P. de Silva, P. Data, Y. Takeda, S. Minakata, J. Am. Chem. Soc. 2020, 142, 1482-1491.

[12] Y. Takeda, M. Okazaki, S. Minakata, Chem. Commun. 2014, 50, 10291-10294.

[13] C. Adachi, M. A. Baldo, M. E. Thompson, S. R. Forrest, J. Appl. Phys. 2001, 90, 5048-5051.

[14] L. Pascal, J. J. V. Eynde, V. Van Haverbeke, P. Dubois, A. Michel, U. Rant, E. Zojer, G. Leising, L. O. Van Dorn, N. E. Gruhn, J. Cornil, J. L. Brédas, J. Phys. Chem. B 2002, 106, 6442-6450.

[15] Y. Yamaguchi, S. Kobayashi, T. Wakamiya, Y. Matsubara, Z.-i. Yoshida, Angew. Chem. 2005, 117, 7202-7206; Angew. Chem. Int. Ed. 2005, 44, 7040-7044.

[16] M. M. Wienk, R. A. J. Janssen, J. Am. Chem. Soc. 1997, 119, 44924501.

[17] M. Uebe, A. Ito, Chem. Asian J. 2019, 14, 1692-1696.

[18] J. Schäfer, M. Holzapfel, B. Mladenova, D. Kattnig, I. Krummenacher, H. Braunschweig, G. Grampp, C. Lambert, J. Am. Chem. Soc. 2017, 139, 6200-6209.

[19] Y. Guo, Z. Ma, X. Niu, W. Zhang, M. Tao, Q. Guo, Z. Wang, A. Xia, J. Am. Chem. Soc. 2019, 141, 12789-12796.

[20] J.-S. Yang, K.-L. Liau, C.-Y. Li, M.-Y. Chen, J. Am. Chem. Soc. 2007, 129, 13183-13192.

[21] A. L. Thompson, T.-S. Ahn, K. R. J. Thomas, S. Thayumanavan, T. J. Martínez, C. J. Bardeen, J. Am. Chem. Soc. 2005, 127, 16348-16349.

[22] M. Uebe, A. Ito, Chem. Asian J. 2019, 14, 1692-1696.

[23] A. Ito, M. Uebe, R. Kurata, S. Yano, H. Fueno, T. Matsumoto, Chem Asian J. 2018, 13, 754-760.

[24] a) N. A. Kukhta, T. Matulaitis, D. Volyniuk, K. Ivaniuk, P. Turyk, P. Stakhira, J. V. Grazulevicius, A. P. Monkman, J. Phys. Chem. Lett. 2017, 8, 6199-6205; b) T. Zhang, X. Wang, Z. An, Z. Fang, Y. Zhang, W. Z. Yuan, ChemPhysChem 2018, 19, 2389-2396.

[25] M. Okazaki, Y. Takeda, P. Data, P. Pander, H. Higginbotham, A. P. Monkman, S. Minakata, Chem. Sci. 2017, 8, 2677-2686.

[26] A. Ito, H. Ino, K. Tanaka, K. Kanemoto, T. Kato, J. Org. Chem. 2002, $67,491-498$. 
WILEY-VCH

\section{FULL PAPER}

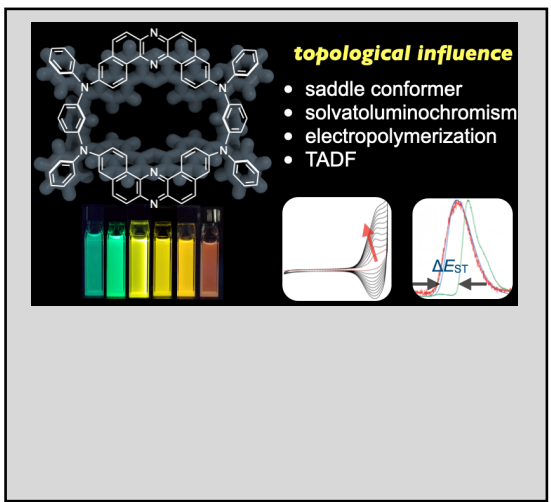

A new donor-acceptor-donor-acceptor macrocyclic $\pi$-conjugated compound comprising of two electron-donors ( $N, N^{\prime}$-diphenyl-mphenylenediamine) and two electron-acceptors (dibenzo[a,j]phenazine) has been synthesized, and its structure and physicochemical properties have been investigated. In comparison with para-linked macrocyclic analogue, the influence of topology of the phenylenediamine donors on properties has been revealed.

Institute and/or researcher Twitter usernames: @Piotr_deSilva, @MinakataLab, @Takephos 